\title{
Association between dietary protein intake and the risk of hypertension: a cross-sectional study from rural western China
}

\author{
Ruru Liu ${ }^{1}$, Shaonong Dang ${ }^{1}$, Hong Yan ${ }^{1}$, Duolao Wang ${ }^{2}$, Yaling Zhao ${ }^{1}$, Qiang Li $^{1}$ and Xiaoning Liu ${ }^{1}$
}

Evidence for an association between dietary proteins and the risk of hypertension in rural Chinese adults, whose diets are protein-poor and unbalanced, is limited. The aim of this study was to investigate the effect of dietary proteins on hypertension among adults of rural western China. A cross-sectional survey was conducted in Hanzhong, China, and 2241 residents were included in the analysis. Logistic regression models were used to examine whether dietary proteins (total, plant and animal protein) were independently correlated with hypertension. The total protein intake was inadequate $(51.7 \mathrm{~g}$ per day for male and $40.1 \mathrm{~g}$ per day for female), accounting for $56-71 \%$ of the Chinese recommended nutrient intakes or adequate intakes. Nearly $80 \%$ of protein intake derived from plants, especially grains, and the proportion derived from plants was higher in females than in males. The daily animal protein intake was $12.1 \mathrm{~g}$ for males and $8.3 \mathrm{~g}$ for females. For females, no significant association was found between hypertension and total protein or plant protein intake. However, animal protein intake was significantly and negatively associated with the risk of hypertension after controlling for demographic characteristics, lifestyle factors, body mass index and other dietary nutrients. In addition, the odds ratio for the upper quartile compared with the bottom quartile was 0.64 (95\% confidence interval, $\mathrm{Cl}: 0.43-0.95, P$ for trend $<0.05)$. Furthermore, a significant decrease of $1.082 \mathrm{~mm} \mathrm{Hg}(95 \% \mathrm{Cl}$ : $0.189-1.975)$ in systolic blood pressure and $0.668 \mathrm{~mm} \mathrm{Hg}(95 \% \mathrm{Cl}: 0.105-1.232)$ in diastolic blood pressure was observed per s.d. increase of animal protein intake in females. For males, we did not observe a significant association between dietary proteins and hypertension or blood pressure. In conclusion, for the western rural Chinese population, especially women, whose dietary protein intake is low and largely derived from plants, the intake of animal protein may be related to a decreased risk of hypertension.

Hypertension Research (2013) 36, 972-979; doi:10.1038/hr.2013.71; published online 11 July 2013

Keywords: animal protein; dietary protein; hypertension; plant protein; rural Chinese

\section{INTRODUCTION}

Hypertension is a common and major public health concern in China, in light of its high prevalence in adults, especially the elderly, and its crucial role in increasing the risk of stroke, coronary heart disease and premature death. ${ }^{1-3}$ Hypertension is estimated to affect 330 million adults (over half of whom are rural inhabitants) in China in 2010, and 1.56 billion adults worldwide are projected to have the disease by 2025. ${ }^{4,5}$ Hypertension can severely damage cardiovascular function and is ranked fifth as a cause of disability-adjusted life years. ${ }^{1}$ With the aging population, this disease exerts an increasingly tremendous social economic burden on health-care resources. ${ }^{5}$ Unfortunately, the treatment and control rates of hypertension remain very low. ${ }^{6,7}$ Considerable evidence has indicated that various environmental factors, including smoking, physical activity and diet quality, can affect blood pressure. ${ }^{8}$ However, there is limited evidence on the effects of diet on hypertension, particularly with respect to nutrients among different populations. In addition, the reported effects of dietary proteins on hypertension are inconsistent throughout the literature. ${ }^{9}$

Systemic reviews and other epidemiological studies have indicated that increasing dietary protein intake reduces the risk of hypertension, which may be most apparent in populations with elevated blood pressure or in the elderly. ${ }^{10,11}$ The research on plant versus animal protein, however, remains inconclusive. Some studies have found that plant protein, but not animal protein, is associated with reduced blood pressure, ${ }^{12}$ whereas others have demonstrated that animal protein may lead to healthy reductions in blood pressure and other cardiovascular markers in healthy and hypertensive persons. ${ }^{11,13,14}$ Moreover, the association between dietary protein and hypertension could be affected by the type of protein, the protein food source and the participants investigated. The Chinese diet is characterized by a higher percentage of plant foods but less animal foods, especially in

${ }^{1}$ Department of Public Health, Xi'an Jiaotong University College of Medicine, Shaanxi, PR China and ${ }^{2}$ Medical Statistics Unit, Department of Epidemiology and Population Health, London School of Hygiene and Tropical Medicine, London, UK

Correspondence: Dr S Dang, Department of Public Health, Xi'an Jiaotong University College of Medicine, Xi'an, Shaanxi 710061, PR China.

E-mail: tjdshn@mail.xjtu.edu.cn

Received 5 January 2013; revised 18 March 2013; accepted 31 March 2013; published online 11 July 2013 
rural areas of China, which differs from that of typical western diets. ${ }^{8,15}$ Measurement of protein intake has been limited to total protein intake in Chinese population regardless of using the method of biological markers, 24-hour dietary recalls or food weighing methods. The evidence for an association between specific sources of protein and blood pressure is limited. Furthermore, it is unclear whether a gender difference in dietary patterns exists, and if so, what the effect of gender difference is on the prevalence of hypertension in China. ${ }^{15,16}$ Therefore, a population-based study was conducted in western China to investigate the prevalence of hypertension and to explore its key risk factors. In this study, we examined the independent effect of dietary protein intake on hypertension, focusing on specific types of protein after controlling for lifestyles, nutrients and other potentially confounding factors.

\section{METHODS}

\section{Study setting}

Hanzhong is located in the Shaanxi Province of western China with a population of 3.82 million, $78.7 \%$ of which live in rural areas. Hanzhong is the first region in China to begin blood pressure monitoring and to promote the prevention and control of hypertension. Most of the monitoring activities and research have been implemented in the Hantai district of Hanzhong. Approximately 55000 inhabitants live in the Hantai District, which is spread over 9 rural townships and includes 75 villages. Farming and migrant work are the main economic activities. The prevalence of hypertension in adults in rural areas is $34.3 \%$, and the dietary habits of the rural adult population are characterized by low caloric and protein intake, similar to other rural areas in China. ${ }^{17}$

A cross-sectional and population-based study was conducted in rural Hantai of Hanzhong in 2010 to investigate the prevalence of hypertension and its risk factors among rural adults. Participants were interviewed in person by trained professional interviewers from the Faculty of Public Health of Xi'an Jiaotong University regarding their blood pressure, demographic and lifestyle characteristics, history of disease and diet. Informed consent was obtained from the participants before the investigation. The study was approved by the Ethics Review Committee, School of Medicine, Xi'an Jiaotong University (Number: 2002001).

\section{Study participants}

This study included adults aged 18 to 80 years living in rural Hantai of Hanzhong. A sample size of 2585 was estimated based on the $18.6 \%$ prevalence of hypertension reported in the 2002 Chinese National Nutrition and Health Survey (2002 NNHS), given $\alpha$ of 0.05 and an error of $15 \%$. Considering an expected $20 \%$ no-response rate, particularly for our investigation with a semiquantitative food frequency questionnaire (FFQ), the sample size was expanded to 3102 . The stratified randomized cluster sampling method was used to obtain the sample. All the nine townships of Hantai were involved as strata. For each township, four villages were sampled randomly. In the sampled village, 90 participants were selected randomly based on a list of residents who were aged 18 to 80 years. All available residents in the study villages were informed of participation in this survey, and the village doctors assisted in the organization of field work, including sampling and investigation.

A total of 3021 participants were investigated. In this study, we excluded 652 participants who reported a history of nutrition-related diseases (stroke, diabetes and hyperlipidemia), those who reported taking antihypertensive medication, as well as those who suffered from several diseases simultaneously. In addition, approximately 128 participants who reported an implausible caloric intake (beyond three s.d.s from the sex-specific $\log _{\mathrm{e}}{ }^{-}$ transformed mean caloric intake ${ }^{18}$ ) or who were missing $>50 \%$ of the responses to food items were excluded. The total data included in the current analysis included 2241 participants (774 for men and 1467 for women). Figure 1 indicates the flow diagram of participants involved in the nutritional study.

\section{Dietary assessments}

A semiquantitative FFQ with nine frequency categories ranging from never to four or more times per day was used to measure the frequency of foods and to estimate the nutrient intake of each participant. ${ }^{19}$ The FFQ was established and revised based on the validated FFQ used for reproductive-aged women in rural western China. ${ }^{20}$ The validity correlations between the mean caloric-adjusted nutrient intake estimated by the FFQ and the mean caloric-adjusted intake from 3-day 24-hour dietary recalls ranged from 0.4 to 0.8 . The correlations of caloricadjusted protein intake ranged from 0.64 to 0.67 across gender groups. ${ }^{20,21}$ Some local foods, including rice crust, serofluid dishes, tofu mixed with preserved leaf vegetables, bacon and rice wine, were added to the questionnaire in view of the special eating habits in rural Hanzhong. The final version of the FFQ included 81 items: cereals and potatoes (10 items), vegetables (22 items), meat and fish (11 items), dairy and beans ( 8 items), fruits (10 items), nuts and snacks (11 items) and alcoholic beverages and soft drink beverages ( 9 items).

During the FFQ investigation, participants were asked to report their frequency of intake and the portion size for each food item with the assistance of an image of a food portion ${ }^{21,22}$ or by the selection of a predefined standard portion when no image was available. Dietary information obtained using the FFQ was coded, computerized and transformed into estimates of daily energy (kcal) and nutrient intake according to the 2004 China Food Composition Table. ${ }^{23}$ Nutrient intake from foods was $\log _{\mathrm{e}}$-transformed and caloric-adjusted to $2100 \mathrm{kcal}$ per day for men and $1700 \mathrm{kcal}$ per day for women by the residual method. ${ }^{24}$ Nutrient reference values were from the Chinese dietary reference intakes. ${ }^{23}$ Given that the participants were rural residents, Chinese dietary reference intakes with a moderate physical activity level was used. The reference values were recommended nutrient intakes by age and gender. Recommended nutrient intakes of protein were as follows: $80 \mathrm{~g}$ per day for men aged 18-59 years; $70 \mathrm{~g}$ per day for men over 60 years; $75 \mathrm{~g}$ per day for women aged 18-59 years; and $65 \mathrm{~g}$ per day for women over 60 years.

\section{Blood pressure and anthropometry}

The day before the medical examination, the participants were informed by the village doctors that they should fast for $\geqslant 8 \mathrm{~h}$ and avoid heavy physical activity. Blood pressure was measured on the right arm of the seated subjects by doctors of the People Hospital of Hanzhong who used a GB 3053-82 mercury sphygmomanometer. Two measurements were taken at 1-min intervals. Systolic and diastolic blood pressures were recorded as phase I and phase V Korotkov sounds. ${ }^{25}$ The average blood pressure of the two measurements was used in the data analyses. According to a criterion formulated by World Health Organization/International Society of Hypertension (WHO/ISH), ${ }^{26}$ hypertension was defined as a systolic blood pressure $\geqslant 140 \mathrm{~mm} \mathrm{Hg}$ and/or a diastolic $\mathrm{BP} \geqslant 90 \mathrm{~mm} \mathrm{Hg}$ or the use of antihypertensive medications. ${ }^{27}$

Anthropometric measures, including body weight, height, waist and hip circumferences and pulse, were collected by trained medical personnel according to standard procedures. Weight was measured on a calibrated electronic scale (Tanita HD-305, Tanita (Shanghai) Trading, Shanghai, China), with participants removing all heavy clothes and shoes. The weight was measured to the nearest $0.1 \mathrm{~kg}$. Height was measured with a height-measuring tape (LD-SG01, Ningbo Land Co-operation, Ningbo, China) to the nearest $0.1 \mathrm{~cm}$. Body mass index (BMI) was calculated as weight in kilograms divided by height in meters squared. ${ }^{28}$

\section{Other measurements}

Standardized interview questionnaires were used to collect the information on demographics (age, gender, race, marital status, education, occupation, transportation, family history of hypertension, and so on), history of disease (hypertension, diabetes, hyperlipidemia and stroke) and lifestyle (physical activity, alcohol intake and cigarette smoking). Education was represented as the total years of schooling, which was classified into primary school (school years $\leqslant 6$ ), secondary school (6-9 school years) and senior school and higher education (school years $>9$ ). The lifestyle questionnaire queried the frequency and time spent in leisure, occupational, farming and household physical activity per month over the past 12 months. Physical activity levels were summarized as low, moderate or high intensity. Cigarette smoking was categorized as never, former and current; the current smokers were further 


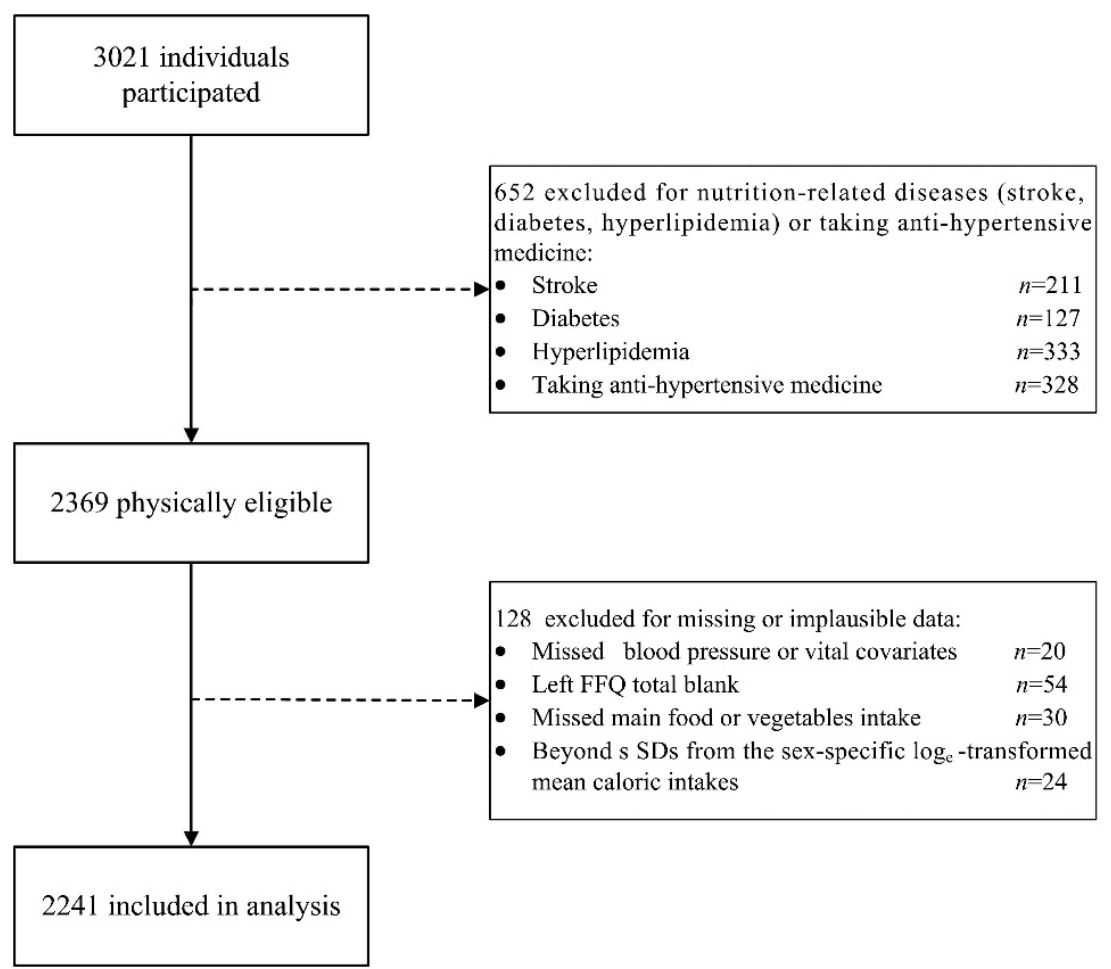

Figure 1 Flow chart for participants involving in the nutritional study.

classified into two categories $(<15$ cigarettes per day and $\geqslant 15$ cigarettes per day) according to average daily cigarette consumption.

\section{Statistical analysis}

The distribution of potential risk factors related to hypertension and major nutrient intake were described according to quartiles of total dietary protein intake. Continuous variables were expressed as caloric-adjusted mean values followed by variance analysis. Categorical variables were reported as percentages and compared by the $\chi^{2}$ test. Principal component analysis was used to identify the economic status of participants for the establishment of a fortune index based on occupation, communication and transportation tools, sources of water and expenses and incomes of the whole family for a month. We selected the first principal component to represent the fortune index and divided it into three groups (poor, moderate and rich) according to tertiles. ${ }^{29}$

Many nutrients were significantly correlated, such as potassium, magnesium, calcium and fiber. ${ }^{30}$ To avoid multicollinearity of nutrients in regression analyses, we drew two principal components by principal component analysis based on all potential nutrients that explained $70 \%$ of the total variance. The first component, 'fat', exhibited the factor loadings of saturated fat, polyunsaturated fat, monounsaturated fat and cholesterol of more than 0.6. The second component was expressed as 'mineral', with the factor loadings of calcium, potassium, fiber and magnesium above 0.83 . Because of the correlation of carbohydrate and sodium with the first two components were below 0.2 , we took the two principal components, carbohydrate and sodium as potential nutrition confounders in regression models.

Multiple logistic regression models were used to evaluate the associations of consumption of total protein, animal protein and plant protein with the incidence of hypertension. Odds ratios (ORs) for hypertension and their $95 \%$ confidence intervals (95\% CIs) were computed for the second through fourth quartile (Q2-Q4) of protein using the first quartile (lowest intake, Q1) as a reference. The linear trend test across quartiles was evaluated using the median value of each quartile as a single continuous variable and was entered into the regression model. Four adjusted models were established for each protein group. Model 1 adjusted for energy only. Model 2 adjusted for the variable in model 1 plus demographic factors, including age, sex, education, family history of hypertension and fortune index. Model 3 adjusted for the variables in model 2 plus non-dietary lifestyle characteristics (physical activity, alcohol intake and smoking). Model 4 adjusted for the variables in model 3 as well as for BMI and potential dietary factors, including carbohydrate, sodium and the two main principal components, 'fat' and 'mineral'. Furthermore, we use multiple linear regression models to explore the effect of one s.d. increase in animal protein intake on blood pressure. All analyses were performed separately for men and women using SAS statistical software version 9.1 (SAS Institute, Cary, NC, USA). A two-tailed $P$ value $<0.05$ was considered statistically significant.

\section{RESULTS}

A total of 592 cases of hypertension (228 men and 364 women) among the 2241 residents were identified in the cross-sectional study. The prevalence of hypertension was $26.4 \%$ (29.5\% in males and $24.8 \%$ in females). The mean age (s.d.) was $48.1 \pm 11.5$ years ( $49.5 \pm 12.2$ years for men and $47.3 \pm 11.2$ years for women). The mean BMI (s.d.) was $22.5 \pm 2.8 \mathrm{~kg} \mathrm{~m}^{-2}$, and overweight individuals made up $\sim 29.1 \%$ of the population $(30.4 \%$ for males and $28.3 \%$ for females). Approximately $24 \%$ of the participants were illiterate, and only $50.2 \%$ had completed 9 years of schooling. Farming and migrant works $(85.9 \%)$ were the major economic sources.

Demographics, lifestyle and nutrient intake were organized according to quartiles of total protein intake by gender and are presented in Table 1. Participants with a higher consumption of dietary protein tended to be older, better educated and wealthier. Those who consumed more protein were also engaged in higher levels of physical activity and were less likely to smoke or drink. Notably, a nonsignificant positive association was observed between total protein intake and alcohol intake in women. Protein consumption was positively associated with carbohydrate, calcium, magnesium, cholesterol and potassium intake and was inversely associated with total fat, unsaturated fat, polyunsaturated fatty acid and sodium intake. 
Table 1 Baseline characteristics and mean energy-adjusted nutrient intakes by quartiles of total protein and gender in 2241 participants in rural Hanzhonga,b

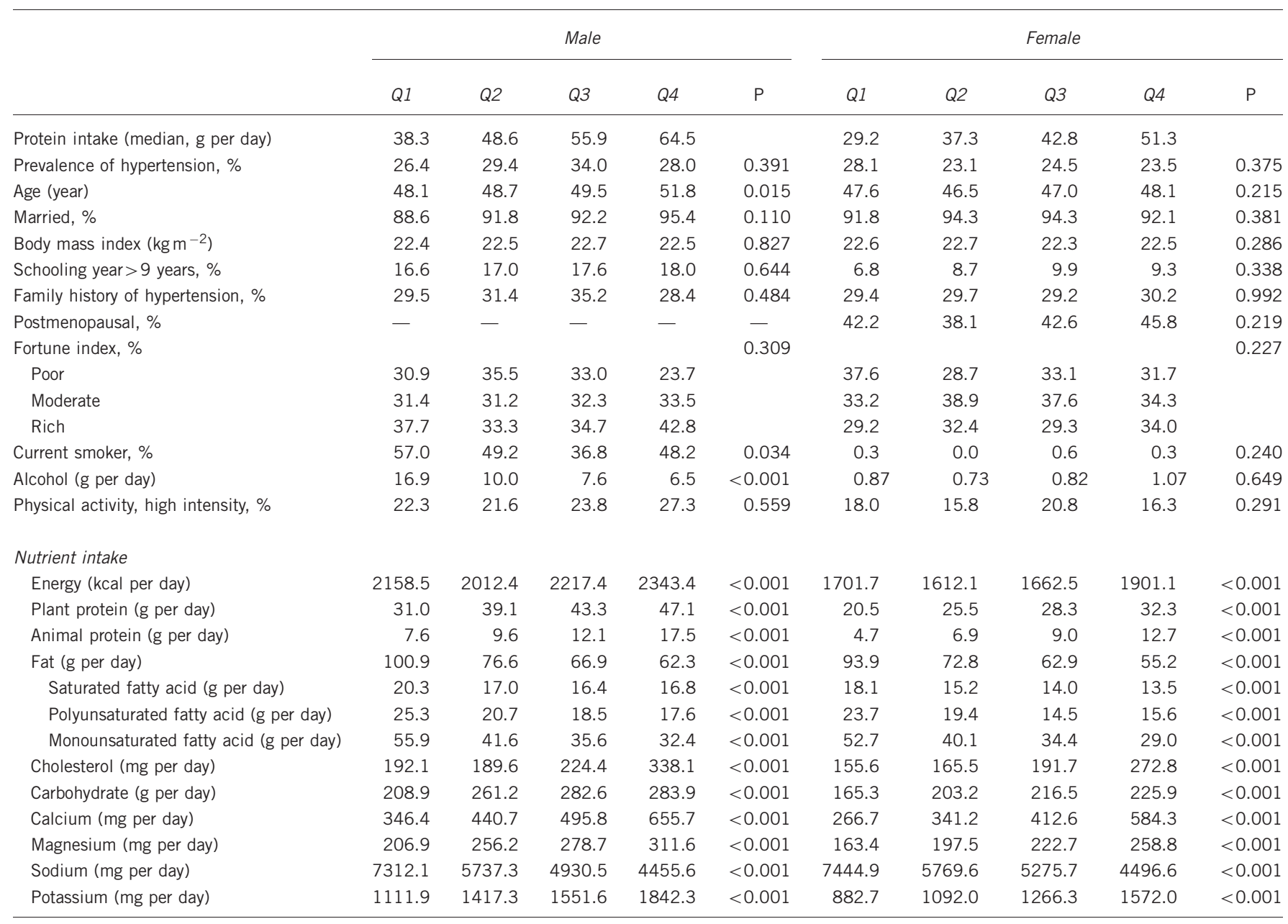

avalues are means or \%.

${ }^{\mathrm{b}} P$-values for any difference in groups derived from analysis of variance for continuous variables or the $\chi^{2}$ test for categorical variables.

Table 2 presents the total protein intake and its sources by age and gender. The protein intake of the participants was severely insufficient ( $51.7 \mathrm{~g}$ per day for males and $40.1 \mathrm{~g}$ per day for females), accounting for $56-71 \%$ of the Chinese recommended nutrient intakes and was especially worse in elderly women. In addition, the sources of protein were largely limited to plant foods, of which cereal was the greatest contributor and provided $57.5 \%$ of total protein. Animal protein occupied merely $20 \%$ of total protein intake, and the most commonly consumed food groups providing animal protein were red meat and dairy products/eggs. Plant protein accounted for a larger proportion of total protein in women than in men (80.1 versus $77.3 \%$ ).

Table 3 presents the ORs for hypertension according to quartiles of total protein, plant protein and animal protein by gender from the four adjusted models. We observed a nonsignificant association between total protein intake and the prevalence of hypertension in the caloric-adjusted model (model 1). The OR for hypertension was 1.12 (95\%CI: 0.72-1.76) for men and 0.87 (95\%CI: 0.62-1.22) for women between the highest and lowest quartiles. After controlling for demographic factors (model 2), non-dietary lifestyle factors (model 3) and BMI and dietary factors (model 4), the nonsignificant association between total protein and hypertension persisted for both genders.
A substantial increase in the risk of hypertension was observed with increasing quartiles of plant protein intake in men and women when adjusted for caloric (model 1). For example, for men, the ORs were $1.08(0.69-1.71)$ in the second quartile, $1.24(0.79-1.94)$ in the third quartile and $1.61(1.04-2.50)$ in the highest quartile compared with the lowest quartile. However, after controlling for potential demographic confounders, lifestyle, BMI and dietary factors, this positive association was no longer significant.

A negative association was observed between animal protein intake and hypertension in women. The caloric-adjusted model (model 1) indicated that the OR of being hypertensive was reduced by $43 \%$ when the intake of animal protein exceeded $11.3 \mathrm{~g}$ per day (quartile 4 , Q4) compared with less than $3.4 \mathrm{~g}$ per day (quartile 1, Q1). The results from models 2 and 3 were very similar, strongly suggesting that the negative association between animal protein and hypertension in women remained, even when controlling for demographic or lifestyle factors. Finally, when we added two main principal components derived from principal component analysis, sodium, carbohydrate and BMI into model 4, the association between animal protein intake and hypertension slightly decreased $(\mathrm{OR}=0.66,95 \% \mathrm{CI}$ : $0.45-0.96)$ but remained significant $(P$ for trend $<0.05$ ). Among men, the association between animal protein intake and hypertension was not 
statistically significant after controlling for energy; the OR for the top quartile was 0.73 (95\%CI: 0.47-1.13). After further controlling for the potential nutrient confounders, the negative association was not significant $(\mathrm{OR}=0.73,95 \% \mathrm{CI}: 0.47-1.15)$.

Table 2 Protein intakes and sources of the participants by gender and age in 2241 participants in rural Hanzhong

\begin{tabular}{|c|c|c|c|c|}
\hline & \multicolumn{2}{|c|}{ Male } & \multicolumn{2}{|c|}{ Female } \\
\hline & $18 \sim$ & $60 \sim$ & $18 \sim$ & $60 \sim$ \\
\hline $\mathrm{n}$ & 608 & 166 & 1267 & 200 \\
\hline $\mathrm{RNI}^{\mathrm{a}}$ & 80 & 75 & 70 & 65 \\
\hline $\begin{array}{l}\text { Protein (g per day) } \\
(\% \text { of RNI) }\end{array}$ & $53.36(66.70)$ & 53.21 (70.95) & $41.04(58.62)$ & $36.91(56.78)$ \\
\hline $\begin{array}{l}\text { Plant protein } \\
\text { (g per day)b }^{\text {b per }}\end{array}$ & 41.29 & 40.94 & 32.48 & 29.83 \\
\hline Cereal & 31.26 & 29.87 & 23.9 & 21.01 \\
\hline Vegetables/fruit & 5.87 & 6.72 & 5.26 & 5.71 \\
\hline Legumes & 3.92 & 4.06 & 3.15 & 2.89 \\
\hline $\begin{array}{l}\text { Animal protein } \\
(\mathrm{g} \text { per day) }\end{array}$ & 12.07 & 12.27 & 8.55 & 7.07 \\
\hline Red meat & 6.79 & 5.83 & 4.33 & 3.08 \\
\hline White meat & 0.99 & 0.73 & 0.70 & 0.43 \\
\hline $\begin{array}{l}\text { Dairy products/ } \\
\text { egg }\end{array}$ & 4.88 & 6.17 & 3.95 & 3.82 \\
\hline
\end{tabular}

aChinese recommended nutrient intakes (RNIs) ${ }^{8}$

bSignificant differences between male and female for each age group, $P<0.001$.
We further explored the magnitude of change in blood pressure and its relationship to animal protein intake (Table 4). An inverse association between animal protein intake and blood pressure was observed in females, but not in males, regardless of systolic or diastolic blood pressure after controlling potential confounders. In the caloric-adjusted model, one s.d. increase in animal protein intake resulted in a decrease of $1.155 \mathrm{~mm} \mathrm{Hg}$ in systolic blood pressure and $0.441 \mathrm{~mm} \mathrm{Hg}$ in diastolic blood pressure in males $(P>0.05)$ and a decrease of $2.145 \mathrm{~mm} \mathrm{Hg}$ systolic and $1.014 \mathrm{~mm} \mathrm{Hg}$ diastolic in females $(P<0.001)$. With additional adjustments for potential demographics factors, the inverse association persisted in women. Furthermore, after controlling for all possible confounders (demographics, lifestyle, BMI and nutrients), the blood pressure changes became smaller but remained strongly significant in females $(-1.082,95 \% \mathrm{CI}$ : -1.975 to -0.189 in systolic blood pressure and $-0.668,95 \% \mathrm{CI}$ : -1.232 to -0.105 in diastolic blood pressure). Animal protein intake appeared to affect systolic blood pressure more than diastolic blood pressure.

\section{DISCUSSION}

This population-based survey demonstrated that dietary protein intake in rural adults of Hanzhong was minimal and was confined to limited sources, which is in agreement with the trend of low caloric and protein intake in other rural areas in China. ${ }^{17,31,32}$ Furthermore, given their poor nutritional status, women deserve more attention with respect to nutrient deficiency. Another important finding was that a significantly negative association was observed between animal protein intake and the risk of hypertension in women, but not in

Table 3 Odd ratios of intake of total protein, plant protein and animal protein for hypertension by gender in 2241 participants in rural Hanzhong ${ }^{\text {a }}$

\begin{tabular}{|c|c|c|c|c|c|c|c|c|c|c|}
\hline \multicolumn{6}{|c|}{ Male } & \multicolumn{5}{|c|}{ Female } \\
\hline Model ${ }^{\mathrm{b}}$ & Q1 & Q2 & Q3 & Q4 & $\mathrm{Pc}^{\mathrm{c}}$ & Q1 & Q2 & Q3 & Q4 & $\mathrm{P}^{c}$ \\
\hline \multicolumn{11}{|c|}{ Total protein } \\
\hline Case/n & $51 / 193$ & $58 / 194$ & $64 / 193$ & $55 / 194$ & & $101 / 366$ & $90 / 367$ & $85 / 367$ & $88 / 367$ & \\
\hline Intake & $<45.4$ & $45.4-51.4$ & $51.4-58.6$ & $>58.6$ & & $<34.4$ & $34.4-40.1$ & $40.1-45.5$ & $>45.5$ & \\
\hline Model 1 & 1.00 & $1.18(0.76-1.84)$ & $1.39(0.90-2.17)$ & $1.12(0.72-1.76)$ & 0.470 & 1.00 & $0.85(0.61-1.18)$ & $0.79(0.57-1.11)$ & $0.87(0.62-1.22)$ & 0.360 \\
\hline Model 2 & 1.00 & $1.12(0.70-1.80)$ & $1.18(0.73-1.90)$ & $0.95(0.58-1.53)$ & 0.895 & 1.00 & $0.93(0.65-1.33)$ & $0.83(0.58-1.21)$ & $0.84(0.58-1.22)$ & 0.278 \\
\hline Model 3 & 1.00 & $1.14(0.71-1.83)$ & $1.22(0.75-1.99)$ & $0.97(0.60-1.61)$ & 0.973 & 1.00 & $0.92(0.64-1.33)$ & $0.81(0.56-1.18)$ & $0.85(0.58-1.24)$ & 0.300 \\
\hline Model 4 & 1.00 & $1.05(0.60-1.84)$ & $1.06(0.56-2.02)$ & $0.81(0.40-1.65)$ & 0.747 & 1.00 & $0.79(0.52-1.20)$ & $0.70(0.43-1.12)$ & $0.78(0.44-1.12)$ & 0.338 \\
\hline \multicolumn{11}{|c|}{ Plant protein } \\
\hline Case/n & 49/193 & $53 / 194$ & $58 / 194$ & $68 / 193$ & & $78 / 366$ & $85 / 368$ & $102 / 366$ & $99 / 367$ & \\
\hline Intake & $<33.4$ & $33.4-39.3$ & $39.3-46.7$ & $>46.7$ & & $<22.3$ & $22.3-26.4$ & 26.4-30.9 & $>30.9$ & \\
\hline Model 1 & 1.00 & $1.08(0.69-1.71)$ & $1.24(0.79-1.94)$ & $1.61(1.04-2.50)$ & 0.026 & 1.00 & $1.09(0.77-1.55)$ & $1.42(1.01-1.99)$ & $1.43(1.01-2.01)$ & 0.016 \\
\hline Model 2 & 1.00 & $1.12(0.69-1.83)$ & $1.19(0.73-1.93)$ & $1.29(0.80-2.08)$ & 0.290 & 1.00 & $1.08(0.74-1.58)$ & $1.35(0.93-1.96)$ & $1.37(0.93-2.00)$ & 0.056 \\
\hline Model 3 & 1.00 & $1.14(0.70-1.86)$ & $1.25(0.76-2.04)$ & $1.37(0.84-2.23)$ & 0.195 & 1.00 & $1.08(0.74-1.59)$ & $1.32(0.91-1.93)$ & $1.34(0.91-1.98)$ & 0.082 \\
\hline Model 4 & 1.00 & $1.17(0.68-2.02)$ & $1.23(0.63-2.40)$ & $1.34(0.60-3.00)$ & 0.604 & 1.00 & $1.01(0.64-1.59)$ & $1.18(0.67-2.06)$ & $1.32(0.67-2.59)$ & 0.354 \\
\hline \multicolumn{11}{|c|}{ Animal protein } \\
\hline Case/n & $66 / 193$ & $52 / 194$ & $57 / 194$ & $53 / 193$ & & $104 / 367$ & $109 / 367$ & $83 / 367$ & $68 / 366$ & \\
\hline Intake & $<5.3$ & $5.3-10.5$ & $10.5-16.4$ & $>16.4$ & & $<3.4$ & $3.4-6.8$ & $6.8-11.3$ & $>11.3$ & \\
\hline Model 1 & 1.00 & $0.71(0.46-1.10)$ & $0.81(0.53-1.24)$ & $0.73(0.47-1.13)$ & 0.235 & 1.00 & $1.06(0.77-1.45)$ & $0.75(0.54-1.05)$ & $0.57(0.40-0.81)$ & $<0.001$ \\
\hline Model 2 & 1.00 & $0.68(0.42-1.10)$ & $0.83(0.52-1.33)$ & $0.72(0.45-1.17)$ & 0.315 & 1.00 & $0.97(0.68-1.38)$ & $0.69(0.48-1.01)$ & $0.60(0.41-0.88)$ & 0.002 \\
\hline Model 3 & 1.00 & $0.69(0.43-1.11)$ & $0.81(0.50-1.30)$ & $0.71(0.44-1.15)$ & 0.270 & 1.00 & $1.00(0.70-1.44)$ & $0.72(0.50-1.05)$ & $0.62(0.42-0.92)$ & 0.006 \\
\hline Model 4 & 1.00 & $0.76(0.49-1.18)$ & $0.81(0.52-1.26)$ & $0.73(0.47-1.15)$ & 0.515 & 1.00 & $1.09(0.78-1.52)$ & $0.78(0.55-1.10)$ & $0.66(0.45-0.96)$ & 0.029 \\
\hline
\end{tabular}

Abbreviations: $\mathrm{BMI}$, body mass index; $\mathrm{Cl}$, confidence of interval; OR, odds ratio.

avalues are energy-adjusted OR $(95 \% \mathrm{Cl})$.

bModel for adjustments, M1: adjusted for energy. M2: M1 further for demographics, including age, sex, education, family history of hypertension and fortune index. M3: M2 further adjusted for lifestyle, including physical activity level, alcohol and smoking. M4:M3 further adjusted for BMI, carbohydrate, sodium and the two principal components. Additionally adjusted for animal protein for effect of plant protein and additionally adjusted for animal protein for effect of plant.

${ }^{c} P$ for trend across quartiles calculated with the median intake of each quartile as a continuous variable. 
Table 4 Estimated blood pressure changes $(\mathrm{mmHg})$ with one s.d. increment of animal protein intake based on different multiple linear regression models

\begin{tabular}{|c|c|c|c|c|c|c|}
\hline \multirow[b]{2}{*}{ Modela } & \multicolumn{3}{|c|}{ Systolic blood pressure } & \multicolumn{3}{|c|}{ Diastolic blood pressure } \\
\hline & Change & $95 \% \mathrm{Cl}$ & $\mathrm{P}$ & Change & $95 \% \mathrm{Cl}$ & $\mathrm{P}$ \\
\hline \multicolumn{7}{|l|}{ Male } \\
\hline Model 1 & -1.155 & $-2.520,0.206$ & 0.096 & -0.441 & $-1.167,0.286$ & 0.234 \\
\hline Model 2 & -0.953 & $-2.283,0.376$ & 0.160 & -0.338 & $-1.094,0.418$ & 0.380 \\
\hline Model 3 & -1.018 & $-2.348,0.312$ & 0.567 & -0.326 & $-1.082,0.430$ & 0.397 \\
\hline Model 4 & -0.697 & $-2.165,0.771$ & 0.351 & -0.163 & $-0.939,0.612$ & 0.679 \\
\hline \multicolumn{7}{|l|}{ Female } \\
\hline Model 1 & -2.145 & $-3.156,-1.133$ & $<0.001$ & -1.014 & $-1.536,-0.491$ & $<0.001$ \\
\hline Model 2 & -1.563 & $-2.530,-0.595$ & 0.002 & -0.972 & $-1.507,-0.437$ & $<0.001$ \\
\hline Model 3 & -1.437 & $-2.417,-0.457$ & 0.004 & -0.901 & $-1.443,-0.359$ & 0.001 \\
\hline Model 4 & -1.082 & $-1.975,-0.189$ & 0.018 & -0.668 & $-1.232,-0.105$ & 0.020 \\
\hline
\end{tabular}

aModel for adjustments, M1: adjusted for energy. M2: M1 further for demographics, including age, sex, education, family history of hypertension and fortune index. M3: M2 further adjusted for lifestyle, including physical activity level, alcohol and smoking. M4:M3 further adjusted for $\mathrm{BMI}$, carbohydrate, sodium and the two principal components. Additionally adjusted for animal protein for effect of plant protein and additionally adjusted for animal protein for effect of plant.

men. Increasing animal protein intake could significantly reduce both systolic and diastolic blood pressure in women. These findings provide important evidence that animal protein may partially reverse blood pressure elevation and suggest that the increasing animal protein intake might be helpful for controlling the prevalence of hypertension in rural areas of China, especially in women.

The food sources and dietary patterns of western and eastern countries differ significantly. ${ }^{32-34}$ In China, the average protein consumption is $65.9 \mathrm{~g}$ per day, which is much lower than that in America and Japan. The Chinese obtain $25.1 \%$ of their total protein intake from animal products and above $60 \%$ from plants, ${ }^{31}$ whereas the corresponding figures of the national survey for the Japanese in 2003 were 41 and $47 \%$ and were 42 and 33\% for the Americans in 1998-1991, respectively. ${ }^{33,34}$ The participants in our study shared the same trend of low protein intake and similar food sources with adults in other rural areas in China, ${ }^{17,31,32}$ but total protein intake of the participants ( $43.5 \mathrm{~g}$ per day) did not reach the national average level in rural areas $(64.6 \mathrm{~g} \text { per day })^{31}$ or the nutrient reference values $(70$ $80 \mathrm{~g}$ per day). ${ }^{23}$ This could be explained by insufficient intake of animal foods (pork was only consumed once a week ${ }^{35}$ ). Notably, in our sample, the nutritional status of women was much poorer than men, particularly with respect to the total protein and animal protein intake.

Our study detected no significant association between total protein intake and hypertension in men or women, although some studies have demonstrated that subjects with a high consumption of total protein experience a relatively low risk of hypertension compared with those who consumed little protein. ${ }^{12}$ With respect to plant protein, a positive relationship with hypertension was observed but was not statistically significant after controlling for demographic characters, consistent with some studies ${ }^{15,36}$ in Asia but in disagreement with others, particularly those of western populations. ${ }^{12}$ However, frequent consumers of animal protein were observed to experience a slightly decreased risk of hypertension, and the association was significant in women, independent of lifestyle and dietary confounders. Furthermore, the reduction of blood pressure, especially systolic blood pressure, was significantly associated with increasing animal protein intake in women. This finding suggests that increasing intake of animal protein might be helpful to control blood pressure, especially in those female adults with a dietary pattern of low animal protein intake.

There are several possible reasons for the difference between our results and others. First, a body of experimental and clinical evidence has indicated that a balanced dietary pattern, containing adequate dietary protein, is essential to maintain proper function and lower chronic disease risk. ${ }^{23,37}$ Thus, a rationale diet may have a positive effect in an unbalanced-nutrition population, specifically in less nourished subjects. ${ }^{38}$ Attention should be paid to the fact that the consumption of animal protein in the participants of our study was far lower than the Chinese recommended nutrient intakes, especially in women. Therefore, in our study, the poor protein nutrition of women may partially be responsible for the gender difference in the effects of animal protein on hypertension. Second, although the reason that plant protein intake might be associated with the elevated risk of hypertension was unclear; ${ }^{36}$ however, this association in our study might be confounded by carbohydrate intake. Some researchers have suggested that carbohydrate intake is a possible risk factor for hypertension. ${ }^{38,39}$ For the Chinese, carbohydrate intake is mainly derived from plant foods such as cereals, and carbohydrate intake is generally higher than in western population. The data from the national survey of China indicated that the mean carbohydrate intake was $329.7 \mathrm{~g}$ per day in Chinese rural residents, whereas this figure was 280.0 g per day in the Americans, ${ }^{31,40}$ and over one-half of the protein intake was obtained from grains in Chinese rural residents. In our study, $\sim 53.1 \%$ of protein was from cereal, and a strong positive correlation was also observed between carbohydrate and total protein intake or plant protein intake $(r=0.62, P<0.01 ; r=0.79, P<0.01)$. Moreover, among protein consumed by women, $\sim 80.1 \%$ was from plant foods, which was slightly higher than that consumed by men $(77.3 \%)$. These data indicate that plant foods are sources of both carbohydrates and proteins for the Chinese, and it is likely that the association between plant protein intake and hypertension in our study is confounded by carbohydrate intake to some extent. Finally, another possible explanation for the gender difference is that cigarette smoking may weaken the association between diet and disease. ${ }^{41,42}$ In our study, most of the smokers were men, which may account to some extent for the insignificant effect on men. In addition, ovarian hormones might affect the association between protein and blood pressure among women. ${ }^{43}$

The biological mechanism by which dietary protein influences the risk of hypertension and the varying effects of plant protein and animal protein intake remain unclear. One possible explanation is that specific amino-acids abundant in animal protein may lead to changes in the blood vessel wall or in the central nervous system, thereby protecting the cardiovascular system. ${ }^{44}$ Plant protein makes up a larger proportion of the Chinese diet than does protein from animal sources, but its nutritional quality is lower as an incomplete protein, unless specific foods are combined for protein complementarity. ${ }^{45,46}$ Furthermore, diets rich in sulfated amino acids such as L-arginine, taurine and methionine, which are diets rich in animal foods, have been suggested to be relevant to the protective effects of lowering blood pressure levels in human. ${ }^{46}$ In animal trials, other amino-acids abundant in animal protein, including tryptophan and tyrosine, have also exhibited a chronic antihypertensive effect. ${ }^{47}$

The strengths of the current study include large-scale recruitment of individuals living in the rural areas, strict eligibility criteria, 
sex-specific analysis and excellent adherence to the survey. However, there are a number of potential limitations. First, the prevalence of hypertension and the dietary protein intake of adults was investigated simultaneously according to the cross-sectional design, so it is difficult to reveal the real causal association. ${ }^{48}$ Second, the survey was conducted at a single site, which may restrict the application of the results to broader populations. Third, the FFQ data were self-reported and therefore may have been affected by the knowledge of food portions and composition and by the ability to recall the foods that the participants consumed. ${ }^{49}$ Finally, in this cross-sectional study, even after controlling for some potential confounders, we cannot fully rule out all other unobserved confounding factors. ${ }^{10}$ Therefore, we adjusted for major affecting factors in our study, including sociodemographic status and lifestyle, which may possibly confound the association between diet and hypertension that has been reported in previous studies. We also controlled for other nutrients that could interfere with the effect of dietary protein on blood pressure. For example, excessive intake of sodium is regarded as an important factor that can elevate blood pressure, and we observed that participants with a higher intake of protein tended to take in less sodium. Therefore, we adjusted for sodium in the final models. However, the effect of sodium on blood pressure in the Chinese population appears to be limited, because excessive sodium intake was very common among our participants, but no significant risk of hypertension related to dietary sodium was observed $(P>0.10)$, which is in agreement with other Chinese studies. ${ }^{50}$

In summary, our study provides worthy information on the dietary and nutritional status of rural Chinese residents as well as the association between dietary protein intake and hypertension in this population. We found that women exhibited poor nutritional status and consumed proteins mainly from plant sources. Animal protein intake was negatively associated with a lower risk of hypertension in women, but no significant relationship was observed between total or plant protein intake and blood pressure. Furthermore, larger-scale cohort studies are needed to evaluate our findings and to examine the effect of amino acids or protein from specific sources in broader populations. The results of this study imply that increased animal protein intake might be helpful in controlling the prevalence of hypertension in rural areas of China, especially in women consuming an unbalanced diet with low animal protein intake.

\section{CONFLICT OF INTEREST}

The authors declare no conflict of interest.

\section{ACKNOWLEDGEMENTS}

This work was supported by the China Medical Board (NO. 08-925). We express our appreciation to all participants in our study for their participation and co-operation, to the professors and students of the school of Medicine, Xi'an Jiaotong University, to the doctors of the People's Hospital of Hanzhong and to the village doctors for their co-operation and organization in the data collection.

1 Ezzati M, Lopez AD, Rodgers A, Murray CJL. Comparative quantification of health risks: the global and regional burden of disease attributable to selected major risk factors. World Health Organization, Geneva, Switzerland, 2004.

2 Hajjar I, Kotchen TA. Trends in prevalence, awareness, treatment, and control of hypertension in the United States, 1988-2000. JAMA 2003; 290: 199-206.

3 Wang Y, Wang QJ. The prevalence of pre-hypertension and hypertension among US adults according to the new joint national committee guidelines: new challenges of the old problem. Arch Intern Med 2004; 164: 2126-2134.

4 Li YC, Wang LM, Jiang Y, Li XY, Zhang M, Hu N. Prevalence of hypertension among Chinese adults in 2010. Zhonghua Yu Fang Yi Xue Za Zhi 2012; 46: 409-413.
5 Kearney PM, Whelton M, Reynolds K, Munter P, Whelton P, He J. Global burden of hypertension: analysis of worldwide data. Lancet 2005; 365: 217-223.

6 Ong KL, Cheung BM, Man YB, Lau CP, Lam KS. Prevalence, awareness, treatment, and control of hypertension among United States adults 1999-2004. Hypertension 2007; 49: 69-75.

7 Wang ZW, Wu YF, Zhao LC, Li Y, Yang J, Zhou BF. Co-Operative Research Group of the Study on Trends of Cardiovascular Diseases in China And Preventive Strategy for the 21 st Century. I. Trends in prevalence, awareness, treatment and control of hypertension in middle-aged Chinese population. Zhonghua Liu Xing Bing Xue Za Zhi 2004; 25: 407-411.

8 Forman JP, Stampfer MJ, Curhan GC. Diet and Lifestyle Risk Factors Associated With Incident Hypertension in Women. JAMA 2009; 302: 401-411.

9 Hermansen K. Diet, blood pressure, and hypertension. $\mathrm{Br} J$ Nutr 2000; 83 . S113-S119.

10 Altorf-van der Kuil W, Engberink MF, Brink EJ, van Baak MA, Bakker SJ, Navis G, van 't Veer P, Geleijnse JM. Dietary protein and blood pressure: a systematic review. PolSOne 2010; 5: e12102.

11 Hodgson JM, Burke V, Beilin LJ, Puddey IB. Partial substitution of carbohydrate intake with protein intake from lean red meat lowers blood pressure in hypertensive persons. Am J Clin Nutr 2006; 83: 780-787.

12 Elliott P, Stamler J, Dyer AR, Appel L, Dennis B, Kesteloot H, Ueshima H, Okayama A Chan $\mathrm{Q}$, Garside DB, Zhou B. Association between protein intake and blood pressure the INTERMAP Study. Arch Intern Med 2006; 166: 79-87.

13 Appel LJ. The effects of protein intake on blood pressure and cardiovascular disease. Curr Opin Lipidol 2003; 14: 55-59.

14 Iso H, Sato S, Kitamura A, Naito Y, Shimamoto T, Komachi Y. Fat and protein intakes and risk of intraparenchymal hemorrhage among middle-aged Japanese. Am Epidemiol 2003; 157: 32-39.

15 Liu L, Ikeda K, Yamori Y. Inverse relationship between urinary markers of animal protein intake and blood pressure in Chinese: results from the WHO Cardiovascular Disease and Alimentary Comparison (CARDIAC) Study. Int J Epidemiol 2002; 31 227-233.

16 Chen Y, Lü J, Li LM, He PP, Yu CQ. Effects of diet and physical activity factors on blood pressure in nine provinces of China: a longitudinal analysis. Zhonghua Liu Xing Bing Xue Za Zhi 2010; 35: 500-505.

17 Liu RR, Dang SN, Yan H, Li Q, Zhao YL, Liu XN. Study on dietary patterns and nutrients intakes in rural residents in Hanzhong of Shaanxi Province. Wei Sheng Yan Jiu 2012; 41: 145-151.

18 Park Y, Spiegelman D, Hunter DJ, Albanes D, Bergkvist L, Buring JE, Freudenheim JL, Giovannucci E, Goldbohm RA, Harnack L, Kato I, Krogh V, Leitzmann MF, Limburg PJ, Marshall JR, McCullough ML, Miller AB, Rohan TE, Schatzkin A, Shore R, Sieri S, Stampfer MJ, Virtamo J, Weijenberg M, Willett WC, Wolk A, Zhang SM, Smith-Warner SA. Intakes of vitamins A, C, and $E$ and use of multiple vitamin supplements and risk of colon cancer: a pooled analysis of prospective cohort studies. Cancer Causes Control 2010; $21:$ 1745-1757.

19 Gibson RS. Principles of Nutritional Assessment, 2nd edn. Oxford University Press, 2005, pp 46-50.

20 Cheng Y, Yan H, Dibley MJ, Shen Y, Li Q, Zeng L. Validity and reproducibility of a semiquantitative food frequency questionnaire for use among pregnant women in rural China. Asia Pac J Clin Nutr 2008; 17: 166-177.

21 Cheng Y, Dibley MJ, Zhang X, Zeng L, Yan H. Assessment of dietary intake among pregnant women in a rural area of western China. BMC Public Health 2009; 9: 222.

22 Dang SN, Wang ZJ, Kang YJ, Xing Y, Yan H. Study on the dietary pattern assessed with semi-quantitative food-frequency questionnaire among rural Tibetan women with children younger than 2 years in Lhasa city. Zhonghua Liu Xing Bing Xue Za Zhi 2010; 31: 394-399.

23 Institute of Nutrition and Food Safety, China CDC China Food Composition 2004. Peking University Medical Press, Beijing, PR China, 2005.

24 Willett W, Stampfer MJ. Total energy intake: implications for epidemiologic analyses. Am J Epidemiol 1986; 124: 17-27.

25 Korotkov NS. A contribution to the problem of methods for the determination of the blood pressure. In: Ruskin A (ed). Classics in Arterial Hypertension. Charles C Thomas, Springfield, IL, USA, 1956: 127-133.

26 Cifkova R, Erdine S, Fagard R, Farsang C, Heagerty AM, Kiowski W, Kjeldsen S, Lüscher T, Mallion JM, Mancia G, Poulter N, Rahn KH, Rodicio JL, Ruilope LM, van Zwieten P, Waeber B, Williams B, Zanchetti A. ESH/ESC Hypertension Guidelines Committee. Practice guidelines for primary care physicians: 2003 ESH/ ESC hypertension guidelines. J Hypertens 2003; 21: 1779-1786.

27 National Cholesterol Education Program (NCEP) Expert Panel on Detection, Evaluation, and Treatment of High Blood Cholesterol in Adults (Adult TreatmentPanel III). Third Report of the National Cholesterol Education Program (NCEP) Expert Panel on Detection, Evaluation, and Treatment of High Blood Cholesterol in Adults (Adult Treatment Panel III) final report. Circulation 2002; 106: 3143-3421.

28 Chinese team for the obesity. The recommendations of Chinese adults body mass index classification. Zhonghua Yu Fang Yi Xue Za Zhi 2001; 35: 349-350.

29 Filmer D, Pritchett LH. Estimating wealth effects without expenditure data-or tears: an application to educational enrollments in states of India. Demography 2001; 38 $115-132$.

30 Willett W. Nutritional Epidemiology, 2nd edn. Oxford University Press, New York, NY USA, 1998, pp 279-281.

$31 \mathrm{He}$ YN, Zhai FY, Wang ZH, Wang HJ, Hu YS, Yang XG. The status and trend for dietary pattern of energy, protein and fat in Chinese residents. Ying Yang Xue Bao 2005; 27: 358-365. 
32 Zhang B, Wang HJ, Du WW. The trends of nutrients intake of Chinese residents in nine provinces from 1989-2009 $(\square)$ the energy intake trend of Chinese adults aged 18-49 years. Ying Yang Xue Bao 2011; 33: 237-242.

33 Ministry of Health. Labour and welfare Kokumin Kennko-Eiyo Chousa. The National Nutrition Survey in Japan, 2003. Daiichi Shuppan, Tokyo, Japan, 2006, in Japanese.

34 Smit E, Nieto FJ, Crespo CJ, Mitchell P. Estimates of animal and plant protein intake in US adults: results from the Third National Health and Nutrition Examination Survey, 1988-1991. J Am Diet Assoc 1999; 99: 813-820.

35 Liu RR, Dang SN, Yan H, Li Q, Zhao YL, Liu XN, Yang RH, Ren Y. Dietary patterns and its relationship with hypertension in rural residents in Hanzhong of Shaanxi Province. Zhonghua Liu Xing Bing Xue Za Zhi 2012; 33: 37-41.

36 Umesawa M, Sato S, Imano H, Kitamura A, Shimamoto T, Yamagishi K, Tanigawa T, Iso $\mathrm{H}$. Relations between protein intake and blood pressure in Japanese men and women: the Circulatory Risk in Communities Study (CIRCS). Am J Clin Nutr 2009; 90: 377-384.

37 Expert Panel on Detection, Evaluation,and Treatment of High Blood Cholesterol in Adults. Executive summary of the Third Report of the National Cholesterol Education Program (NCEP) Expert Panel on Detection, Evaluation, and Treatment of High Blood Pressure (Adult Treatment Panel III). JAMA 2001; 285: 2486-2497.

38 Appel LJ, Sacks FM, Carey VJ, Obarzanek E, Swain JF, Miller ER 3rd, Conlin PR, Erlinger TP, Rosner BA, Laranjo NM, Charleston J, McCarron P, Bishop LM. OmniHeart Collaborative Research Group. Effects of protein, monounsaturated fat, and carbohydrate intake on blood pressure and serum lipids. Results of the OmniHeart Randomized Trial. JAMA 2005; 294: 2455-2464.

$39 \mathrm{He} \mathrm{J,} \mathrm{Wofford} \mathrm{MR,} \mathrm{Reynolds} \mathrm{K,} \mathrm{Reynolds} \mathrm{K,} \mathrm{Chen} \mathrm{J,} \mathrm{Chen} \mathrm{CS,} \mathrm{Myers} \mathrm{L,} \mathrm{Minor} \mathrm{DL,}$ Elmer PJ, Jones DW, Whelton PK. Effects of dietary protein supplementation on blood pressure: a randomized, controlled trial. Circulation 2011; 124: 589-595.

40 U.S. Department of Health and Human Services Centers for Disease Control and Prevention National Center for Health Statistics. Intake of calories and selected nutrients for the United States Population 1999-2000. http://www.cdc.gov/nchs/ nhanes

41 Nakamura K, Nagata C, Oba S, Takatsuka N, Shimizu H. Fruit and vegetable intake and mortality from cardiovascular disease are inversely associated in Japanese women but not in men. J Nutr 2008; 138: 1129-1134.

42 Genkinger JM, Platz EA, Hoffman SC, Comstock GW, Helzlsouer KJ. Fruit, vegetable, and antioxidant intake and all-cause, cancer, and cardiovascular disease mortality in a community-dwelling population in Washington County, Maryland. Am J Epidemiol 2004; 160: 1223-1233.

$43 \mathrm{McC}$ arthy JJ. Gene by sex interaction in the etiology of coronary heart disease and the preceding metabolic syndrome. Nutr Metab Cardiovasc Dis 2007; 17: 153-161.

44 Obarzanek E, Velletri PA, Cutler JA. Dietary protein and blood pressure. JAMA 1996; 275: 1598-1603

45 He J, Klag MJ, Whelton PK, Chen JY, Qian MC, He GQ. Dietary macronutrients and blood pressure in southwestern China. J Hypertension 1995; 13: 1267-1274.

46 Kihara M, Fujikawa J, Ohtaka M, Mano M, Nara Y, Horie R, Tsunematsu T, Note S, Fukase M, Yamori Y. Interrelationships between blood pressure, sodium, potassium, serum cholesterol, and protein intake in Japanese. Hypertension 1984; 6: 736-742.

47 Resources Council, Science and Technology Agency Standard tables of food composition in Japan: amino acid composition of foods. Revised ed. Bureau of Ministry of Finance, Tokyo, Japan, 1986, in Japanese.

48 Morgenstern H, Thomas D. Principles of study design in environmental epidemiology. Environ Health Perspect 1993; 101: 23-38.

49 Shimokawa $\mathrm{H}$, Vanhoutte PM. Dietary omega-3 fatty acids and endothelium-dependent relaxations in porcine coronary arteries. Am J Physiol 1989; 256: H968-H973.

50 Liu ZQ. Salt intake trend in Chinese adults from 1982 2002 and the association between salt and the risk of hypertension. Zhong Hua Gao Xue Ya Za Zhi 2009; 17 : 482-485. 